\title{
IDENTIDADE E A REPRESENTAÇÃO DO FEMININO EM JANE EYRE: RAZÃO, EMOÇÃO E OPRESSÃO ${ }^{1}$
}

\author{
KARINA MORAES KURTZ (UFSM)
}

\begin{abstract}
RESUMO: O presente artigo tem como objeto de análise o romance autobiográfico ficcional de Charlotte Brontë, Jane Eyre. O puritanismo e o moralismo religioso que divide a maneira de pensar da personagem principal, Jane, marca a culpa religiosa à qual a personagem é submetida durante sua vida. Os objetivos englobam apontar a repressão sexual feminina na era vitoriana, o modo como ocorre a formação de identidade da protagonista diante de um ambiente hostil e como o romance de Charlotte é ao mesmo tempo uma narrativa de resistência. Entre outros fatores primordiais para compreender a oscilação entre a intuição e os conceitos éticos que permeiam a formação de Jane, estão as alegorias presentes na narrativa, as referências bíblicas, as superstições e diversos símbolos. Este trabalho leva em consideração a importância de obras que evidenciam formas de resistência diante de regimes opressivos e autoritários em relação ao sexo feminino. Conclui-se que os estudos literários são primordiais como uma inesgotável fonte que produz críticas e denúncias de ideologias impostas como forma de controle social, principalmente através da religião e dos sistemas educacionais opressivos.
\end{abstract}

PALAVRAS-CHAVE: Romance Autobiográfico. Opressão. Moralismo Religioso.

Abstract: This article analyzes the fictional autobiographical novel by Charlotte Brontë, Jane Eyre. Puritanism and religious moralism that divides the way of thinking of the main character, Jane, marks the religious guilt to which the character is subjected during her life. The goals include pointing to female sexual repression in the Victorian era, how the protagonist's identity formation takes place in the face of a hostile environment and the way Charlotte's novel is a narrative of resistance. Among other key factors to understand the oscillation between intuition and the ethical concepts that permeate Jane's formation are the allegories present in the narrative, Biblical references, superstitions, and various symbols. This paper takes into account the importance of works that demonstrate forms of resistance to oppressive and authoritarian regimes in relation to women. It is concluded that literary studies are primordial as an inexhaustible source that produces criticism and denunciations of ideologies imposed as a form of social control, mainly through religion and oppressive educational systems.

KEYWORDS: Autobiographical Novel. Oppression. Religious Morality.

\section{INTRODUÇÃO}

O objeto de análise utilizado, Jane Eyre, romance de autobiografia ficcional de Charlotte Brönte, publicado em 1847, apresenta Jane como personagem principal, que ao longo da narrativa demonstra o seu descontentamento com o estereótipo que lhe é imposto durante a

\footnotetext{
${ }^{1}$ Este é o título da pesquisa apresentada no evento I SETEDI em maio de 2019 na Universidade Federal de Santa Maria. Este artigo é fruto de uma pesquisa de Mestrado em Letras, de minha autoria, podendo conter citações e/ou passagens que fazem parte da fundamentação teórica. A conclusão desta pesquisa e sua versão final ocorreram em janeiro de 2020. E-mail: kakakurtz@gmail.com
} 


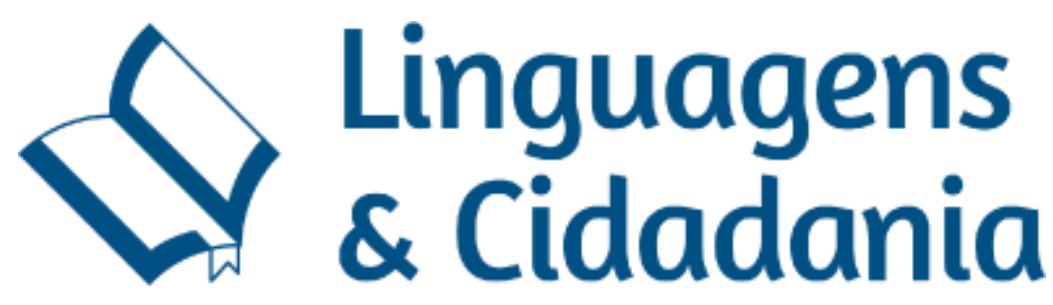

sociedade inglesa vitoriana - entende-se como o período de reinado da Rainha Vitória, de 1837 a 1901 - conhecida por ser uma época conservadora e puritana. De acordo com Monteiro (1998), a rainha Vitória "atribuía o sucesso do seu reinado à moralidade da corte e à harmonia da vida doméstica", entendendo o movimento em defesa dos Direitos da Mulher, "como uma ameaça à virtude do sexo 'frágil'”. Essa visão negativa promoveu a intensificação da repressão, principalmente sexual, no âmbito familiar da época.

A imagem de que a mulher era sexualmente passiva encontrou, na época, respaldo no mundo da medicina. Em 1857, William Acton (1813-1875), em The Functions and Disorders of the Reproductive Organs, corroborava a ideologia predominante, ao assegurar a seus leitores que as únicas paixões sentidas pelas mulheres eram pelo lar, filhos e deveres domésticos. Segundo o referido autor, a mulher submetia-se ao marido só para satisfazê-lo e, se não fosse pelo prazer da maternidade, preferia não ter atenção sexual (MONTEIRO, 1998, p.61).

Jane simboliza uma quebra no padrão de comportamento esperado da mulher neste período, buscando por autonomia, independência financeira, liberdade, equidade dos gêneros, direito a construção de sua identidade com integridade e respeito e o fim da opressão do sistema patriarcal autoritário. Enquanto trava dentro si um conflito com suas raízes morais protestantes e sua paixão pelo personagem Rochester.

A protagonista sofre demasiadamente pelo conflito de ideias que ocorre entre seus dois polos existenciais, a razão e a emoção. Percebe suas próprias necessidades, porém acompanhadas da culpa moral religiosa imposta e, ao mesmo tempo, sente o desejo de mudança, o desenvolvimento de sua identidade como mulher, e o fato de não precisar depender da permissão do sexo masculino sob nenhum aspecto. No desenrolar da trama, a personagem Jane consegue atingir sua autonomia tornando-se professora, porém, recebe uma quantia exígua que não cobre nem mesmo suas despesas com comida e moradia.

O romance não só é uma crítica ao sistema autoritário a que Brönte e outras mulheres eram submetidas, é uma crítica inclusive ao sistema educacional da época, representado de maneira severa e opressora no decorrer da história, fato que conduz Jane a se tornar uma professora gentil e preocupada com seus alunos. A cruel realidade da sociedade inglesa e a desi-

Linguagens \& Cidadania, v. 21, n. esp., jan./dez. 2019 - art. 1 pág. 2 


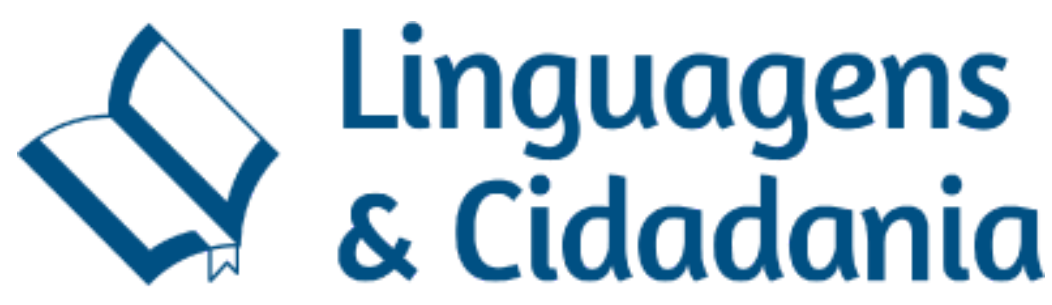

gualdade das classes sociais são imparciais com Jane durante a trama de eventos, Jane sente uma igualdade social perante os outros apenas quando recebe uma graúda herança de família que ocorre no final da narrativa. De acordo com Beauvoir (2016), a grande maioria das mulheres da sociedade vitoriana partilhavam do mesmo sentimento da personagem, desejavam respeito e igualdade de direitos, autonomia e uma posição digna nas ciências, nas artes e no ambiente doméstico.

A presente pesquisa é de cunho bibliográfico/documental do tipo qualitativa/exploratória, pois se trata de uma análise com base em um objeto de estudo literário, juntamente com o auxílio de outras obras que auxiliarão a análise, como livros e outros materiais que complementarão a bibliografia para a interpretação final dos dados a serem coletados e descritos no texto final da dissertação. É qualitativa pois propõe analisar e interpretar comportamentos e relações sociais de um determinado grupo no período histórico dos séculos XVIII e XIX da Inglaterra vitoriana, e porque não pretende apresentar números e estatísticas em seus resultados, mas sim, chegar a discernimentos e reflexões.

Esse processo de análise levará em consideração o tempo, espaço, local e características sociais sobre o período histórico e, em contraste com a narrativa, para que seja possível traçar um perfil da construção de identidade da personagem Jane e analisar a verossimilhança com o período histórico em destaque.

A primeira etapa será de coleta dos dados bibliográficos e leitura desse respectivo material, bem como a leitura de Jane Eyre e sua releitura tantas vezes forem necessárias para que seja possível traçar uma linha entre os documentos que relatam a realidade da época e o romance autobiográfico ficcional. A importância disto está na formação dos estereótipos femininos da época e como isso influencia a construção da identidade de Jane, assim como a influência das outras personagens femininas em sua vida. Visa também analisar a opressão por parte do sistema patriarcal e o desejo de liberdade e autonomia da personagem; a influência da religião na conduta das mulheres (no romance, e nos dados bibliográficos); comparação acerca do material bibliográ- 


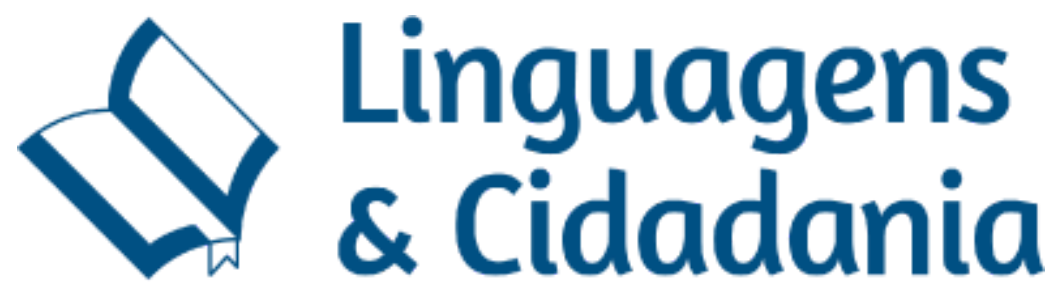

fico em conformidade com Jane Eyre a respeito do sistema educacional do período, a influência das classes sociais descritas no romance e como essas interferem na vida da personagem, e por fim, como as simbologias no romance se comportam e o que supostamente representam.

Após a coleta desse material, será realizada uma divisão a fim de facilitar e organizar o processo de análise e interpretação. Somente após essa minuciosa organização os dados serão de fato interpretados, de modo a estabelecer relações entre os elementos encontrados, em busca das respostas para as hipóteses que surgiram antes da análise e para perguntas que surgirão ao longo da pesquisa, culminando com as considerações finais acerca da pesquisa realizada.

Para a análise, planejamos a reflexão sobre o objeto, à luz dos fundamentos teóricos considerados e, para a interpretação, um movimento em relação à síntese das descobertas feitas, enfatizando aproximações possíveis. [...] É o momento de refazer todo o caminho percorrido, avaliar acertos e erros e levantar novas questões de pesquisa, num processo contínuo. Por isso, o pesquisador deve ser um sujeito inquieto, observador e criativo (AGUIAR e PEREIRA, 2007, p.13).

\section{JANE EYRE E A REPRESENTAÇÃO FEMININA}

A representação da mulher sempre esteve presa ao longo dos séculos às amarras de um sistema patriarcal que a mantinha, e sob muitos aspectos ainda mantém, constantemente sob severa rigidez e restrição de movimentos. A mulher que desejasse se libertar dessa prisão, via-se excluída e se tornava um exemplo causador de medo em outras mulheres que desejassem fazer o mesmo. É o único dos sexos que sempre esteve vetado ao espaço familiar do lar, um espaço restrito onde era permitido somente que ela exercesse toda a sua capacidade em obedecer e servir às necessidades de todos que por ali passassem. A ela foi permitida total liberdade para explorar sua criatividade para o entretenimento da família e do marido, bem como para as atividades domésticas que pudessem surgir, com exceção do direito à sua própria sexualidade e atividades externas ao lar. De acordo com Acton (1867), cabia à dona do lar ser uma moça recatada, delicada e bem comportada, um ser praticamente assexuado, com exceção às prostitutas e às ninfomaníacas. No entanto, jamais poderiam se negar às obrigações sexuais com o marido. Desde 


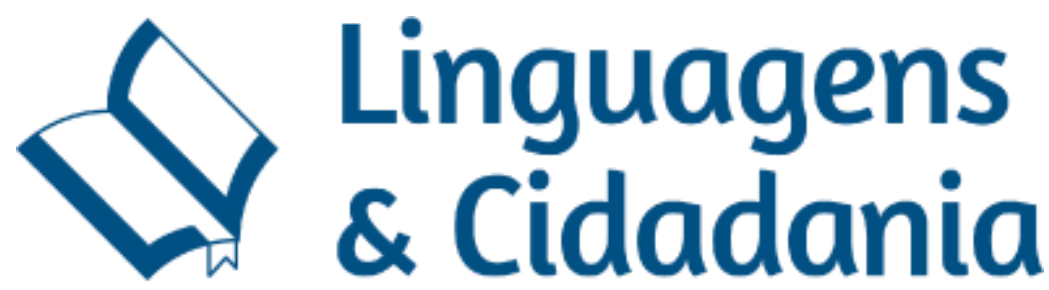

jovem, a menina teria lições como o canto, o bordado, as noções de etiqueta, exclusividade de uma classe social aristocrata do período inglês do século XVIII e XIX (BEAUVOIR, 2016), com intuito de despertar o olhar de algum moço de uma família nobre que a propusesse casamento (MONTEIRO, 1998).

A forma mais fácil e, talvez a mais assustadora, para manter as mulheres sob completa obediência e com a ilusão de vigilância, foi através da religião. A personagem Jane trava uma luta constante em seu interior referente ao amor sentido por Rochester e pelo seu desejo de se sentir amada e valorizada. No entanto, a culpa religiosa a faz sentir que para atingir esse objetivo ela deveria se sacrificar e sofrer constantemente. No entanto, sabemos que a literatura atua como crítica social e abala ideologias utilizadas no controle de massas, sendo a religião uma das mais fortes (EAGLETON, 2006). As irmãs Brönte entram para o mundo literário proporcionando liberdade a todas essas vozes sufocadas diante da opressão do período em que viviam.

Se nos fosse solicitada uma única explicação para o aumento do número de estudos ingleses em fins do século XIX, a melhor resposta nos parece ser "a falência da religião". Em meio ao período vitoriano, essa forma ideológica, tradicionalmente confiável, imensamente poderosa, enfrentava profundos problemas. Já não conquistava os corações e mentes das massas, e sob o duplo impacto das descobertas científicas e da mudança social, seu predomínio, antes inquestionável, corria o risco de desaparecer. Tal fato era muito perturbador para a classe dominante vitoriana, porque a religião é, por todas as razões, uma forma extremamente eficiente de controle ideológico (EAGLETON, 2006, p.33-34).

De acordo com Beauvoir (2016), no século XVIII os costumes permanecem severos para as mulheres, a jovem recebe uma educação básica, então os pais decidem se a casam ou a enviam para um convento. Novamente temos aqui uma demonstração de como a religião maneja o controle da forma de pensar de diversas classes sociais, atuando na decisão das famílias com relação ao futuro da prole feminina.

Excluída do mundo público dos negócios e recolhida ao mundo privado do lar, por injunções de uma estratificação social fundada na diferença dos sexos, era de se esperar que as jovens de 'boa família' recebessem uma educação ou (i)lustração destinada apenas a fazê-las reluzir nas salas de visita e a cativar com o seu brilho o olhar de algum pretendente (MONTEIRO, 1998, p.62). 


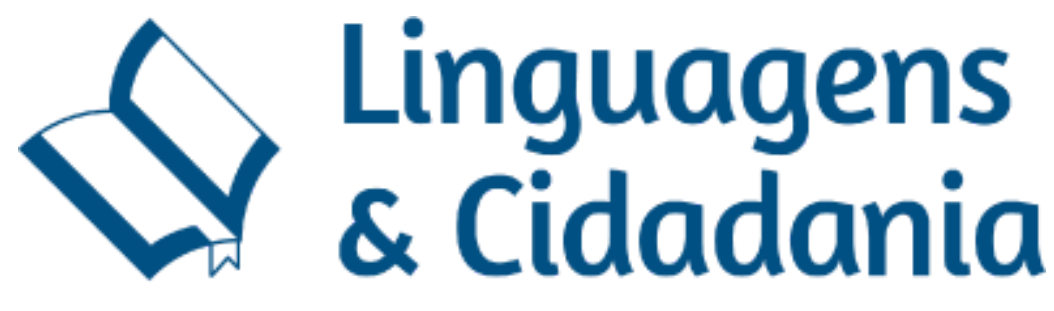

Contudo, a mulher consegue maior liberdade e independência com a decomposição da nobreza e, juntamente, com a falência do sistema religioso, apontado por Eagleton (2006), situação que permite que as mulheres comecem a buscar mais oportunidades para si e passam a não ignorar mais suas vontades e a própria existência do prazer feminino, sendo estes últimos, fatores importantes da formação de identidade e pertencimento igualitário em uma sociedade patriarcal onde a mulher não recebia o devido reconhecimento por suas obrigações e seus talentos nas diversas áreas do conhecimento. As mulheres não desejavam superioridade e controle acerca dos homens, mas sim, o tratamento que eles recebiam desde meninos.

\begin{abstract}
Em verdade, as mulheres nunca opuseram valores femininos aos valores masculinos; foram os homens, desejosos de manter as prerrogativas masculinas, que inventaram essa divisão: pretenderam criar um campo de domínio feminino - reinado da vida, da imanência - tão somente para nele encerrar a mulher; mas é além de toda especificação sexual que o existente procura sua justificação no movimento de sua transcendência: a própria submissão da mulher é a prova disso. O que elas reivindicam hoje é serem reconhecidas como existentes ao mesmo título que os homens e não de sujeitar a existência à vida, o homem à sua animalidade (BEAUVOIR, 2016, p.100).
\end{abstract}

O sistema patriarcal não perdoou as mulheres ao imporem tamanhas exigências, enquanto que ao homem caberia o intelecto, a aventura e a simbologia do herói. As amarras que prendiam os movimentos femininos e o desejo de mudança, a busca pela liberdade, a mordaça que sufocava a voz daquelas que não possuíam o direito de se libertar sem culpa, de escrever um livro, de expor uma pintura, thes era imposta pelos seus próprios pais, irmãos, cônjuges, filhos, netos. Aquela que decidisse ir além seria colocada de lado, excluída da sociedade, e não muito distante do século XIX, seria dada por louca, rebelde, herege, bruxa (ROSSI, 2007).

As mulheres desejavam ter o direito de escolher se queriam ou não seguir carreiras intelectuais ou artísticas, ou mesmo, manter sua situação, e não se sentirem constantemente oprimidas e perseguidas por seus desejos e suas ações. Beauvoir afirma que as mulheres adquiriram o direito às artes no século XIX, embora elas ainda demorariam muito a conseguir algum reconhecimento no mesmo patamar que um homem da mesma área, com o mesmo conhecimento e talento, ou até menos: 


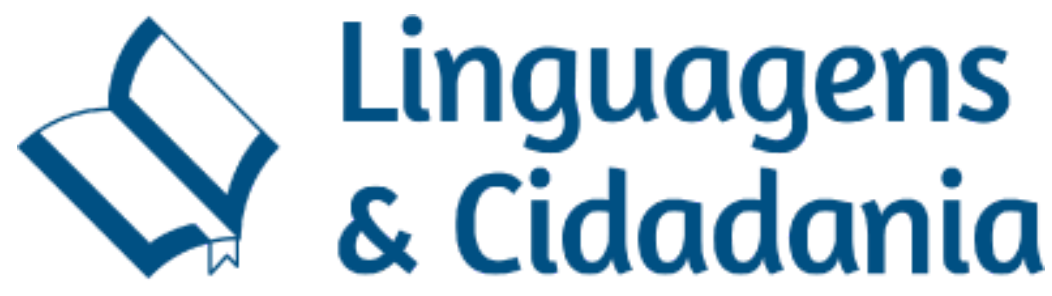

[...] nenhuma, entretanto, atingiu as alturas de um Dante, de um Shakespeare, o que se explica pela mediocridade geral de sua condição. [...] As próprias privilegiadas encontravam em derredor obstáculos que lhes barravam o acesso aos altos picos (BEAUVOIR, 2016, p.152).

O desejo de Jane, assim como de qualquer outra mulher neste período histórico, e ainda presente nos dias atuais, era de conseguir uma posição que a dignificasse, que lhe fizesse sentir importante e ter a sensação de pertencimento, e não ser mera escrava do lar, dos filhos e dos fetiches masculinos. As personagens criadas por Charlotte Brönte são conhecidas por não se conformarem com o estereótipo e a opressão realizada pelos homens, são personagens que comandam essa reviravolta na sociedade inglesa do século XIX. Segundo Doris Goettems, tradutora da versão aqui utilizada:

A importância de Charlotte Brönte é significativa em um momento em que as relações sociais e econômicas da sociedade se transformavam: em uma época onde as mulheres eram consideradas apenas como um mero adorno social, bravamente enfrentou os obstáculos da sociedade através de sua obra. Seus romances falam sobre a opressão da mulher, o que a caracterizam como uma das primeiras mulheres modernas; entretanto, classificá-la apenas como feminista seria uma má-representação de sua verdadeira importância. (GOETTEMS apud BRÖNTE, 2016, p.355).

Beauvoir (2016) afirma que "a burguesia, classe em ascensão e cuja existência se consolida, impõe à esposa uma moral rigorosa", no entanto, "nem os conventos nem o lar conjugal conseguem conter a mulher", ou seja, as mulheres passam a querer uma posição na sociedade, e o meio pelo qual elas conseguem é através da arte, como podemos comprovar com a personagem Jane, e com a escritora Charlotte Brönte, que fora criada dentro das fortes morais protestantes (ROSSI, 2007). A personagem se revela altamente habilidosa nas artes, realiza belíssimos desenhos, é retratada desde criança com um gosto forte pela literatura, embora fosse rechaçada por seu sonho de liberdade. Assim, deve-se destacar a autora da obra, Charlotte Brönte, e suas irmãs, que conseguiram publicar seus livros no século XIX em meio a tamanha opressão e imposições morais. Para Eagleton (2006, p.37) a "literatura foi, sob vários aspectos, um candidato bem adequado a essa empresa ideológica. Como atividade liberal, "humanizadora", podia proporcionar um antídoto poderoso ao excesso religioso e ao extremismo ideológico”. 


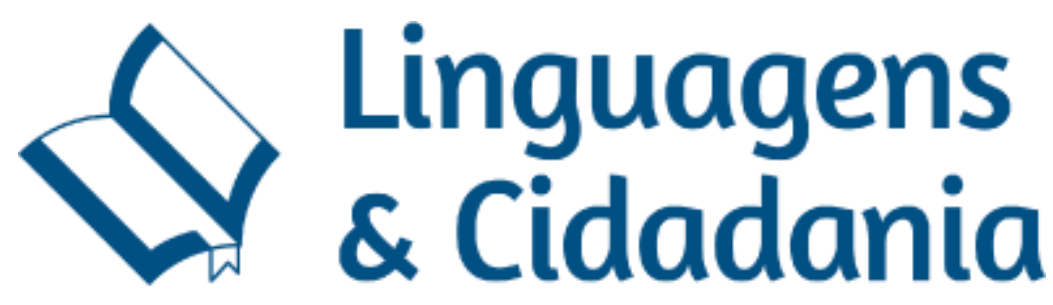

Podemos notar até que ponto a opressão masculina interfere na imagem e no estereótipo das mulheres ao longo da história; ao passo que a literatura é um meio para crítica social, denúncia de inúmeros traumas, memórias sufocadas, sendo ficção ou não, ela pode ser usada como meio de construção negativa em torno de um gênero, credo, etnia, etc. Para Rossi (2007), "não é de se espantar que os textos considerados canônicos, fundadores da tradição literária ocidental, tenham sido escritos por homens (Homero, Dante, Camões, Shakespeare, Goethe, Flaubert etc.)". Visto isso, a imagem das mulheres foi calcada sob dois aspectos: de que ela constitui o que chamamos de "santa", representando a dona de casa, angelical, obediente e serviliente, ou a "vilã", a rebelde, herege, prostituta, o monstro.

Isso fica ainda mais evidente quando se observa como a tradição literária masculina [...] tem representado a mulher no decorrer dos séculos: foi a beleza de Helena que provocou as carnificinas da Guerra de Tróia; foi o amor incondicional que levou Inês de Castro à morte; foi Lady Macbeth que incitou seu marido a matar Duncan por ganância; Dulcinéia, uma lavadeira elevada ao posto de dama, era o motivo último pelo qual Dom Quixote travava suas batalhas imaginárias; Emma Bovary suicidou-se por arrependimento; teria Capitu traído Bentinho Santiago? (ROSSI, 2007, p.21).

A mulher não possuía meios para se defender de tamanhas acusações, porém, foi a sociedade vitoriana a época mais forte e favorável para a mudança dessa realidade; é possível afirmar, segundo Beauvoir (2016), que foi nesse período que elas passaram a conquistar seu espaço nas artes e como estudantes em escolas, constituindo, inclusive, a maioria das salas de aula de Língua Inglesa em Cambridge (EAGLETON, 2006). Neste período surgiram obras literárias com autoria de empoderamento feminino como as irmãs Brönte (Emily e Charlotte), Jane Austen, Mary Wollstonecraft, Virginia Woolf, entre outras que surgiram ao longo dos séculos XVIII e XIX. Assim, sendo altamente influenciadas pelas pioneiras na literatura feminina contra os padrões opressores patriarcais, surgiram outras ao longo dos séculos XX e XXI.

[...] a literatura tem sido um instrumento poderoso de instrução e educação, entrando nos currículos, sendo proposta a cada um como equipamento intelectual e afetivo. Os valores que a sociedade preconiza, ou os que considera prejudicais, estão presentes nas diversas manifestações da ficção, da poesia e da ação dramática. A literatura confirma e nega, propõe e denuncia, apoia e combate, fornecendo a possibilidade de vivermos dialeticamente os problemas (CANDIDO, 1995, p. 175). 


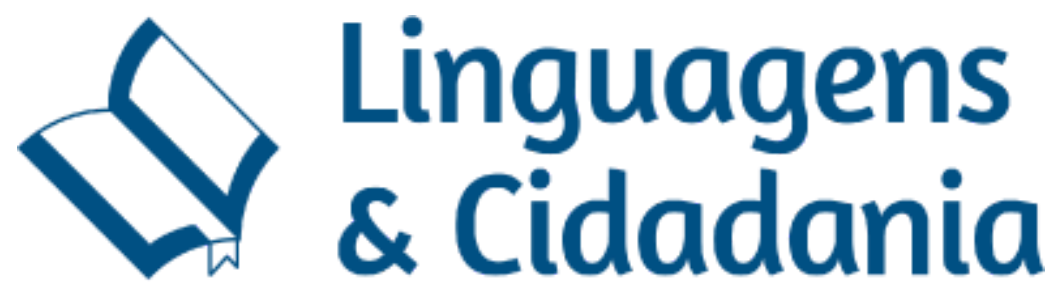

É de extrema importância mencionar que Jane representa as mulheres insatisfeitas e ansiosas por uma mudança que lhes trouxesse liberdade, o poder de transformar e explorar suas identidades, respeito, dignidade, integridade, e reconhecimento social (BEAUVOIR, 2016). Pela semelhança da personagem com Brönte, é comum que leitores confundam ator e autor, personagem com autoria. Embora a verossimilhança esteja presente em inúmeros aspectos da obra, não deixa de ser uma obra ficcional que provocou inúmeras reflexões acerca da personagem e sua trajetória em busca de sua identidade. De acordo com Hall (2015, p.10), "a identidade somente se torna uma questão quando está em crise, quando algo se supõe como fixo, coerente e estável é deslocado pela experiência da dúvida e da incerteza". Jane questiona a si e coloca em dúvida os estereótipos e regimes impostos a sua volta. Se encontra dividida entre seu lado emocional e questiona a opressão sofrida, deseja liberdade e autonomia para tomar decisões por conta própria, ao mesmo tempo em que teme a ira da religião, pois sente-se obrigada a seguir os padrões morais impostos pela igreja.

Em contradição ao desejo de Jane, a educação das mulheres inglesas da época vitoriana deveria ser diferente da educação masculina; de acordo com Ellis (1843), as meninas deveriam ter direito a uma educação de alto nível, pois a mulher era a primeira educadora na vida de um homem, e por isso, carregava consigo o poder e a obrigação de educá-los de maneira correta e dentro dos costumes religiosos da Inglaterra, além de terem uma formação completa em tarefas domésticas.

\section{UM ROMANCE ATEMPORAL}

A presente análise de Jane Eyre é de extrema relevância pois a obra aborda questões pertinentes aos dias atuais, como por exemplo, a opressão da figura feminina, a busca por um espaço livre de discriminações onde a mulher possa construir sua identidade sem ter que depender da permissão do pai ou cônjuge. Ter direito ao livre arbítrio de aceitar sua sexualidade e se relacionar com quem desejar, de buscar reconhecimento em sua carreira profissional, sendo 


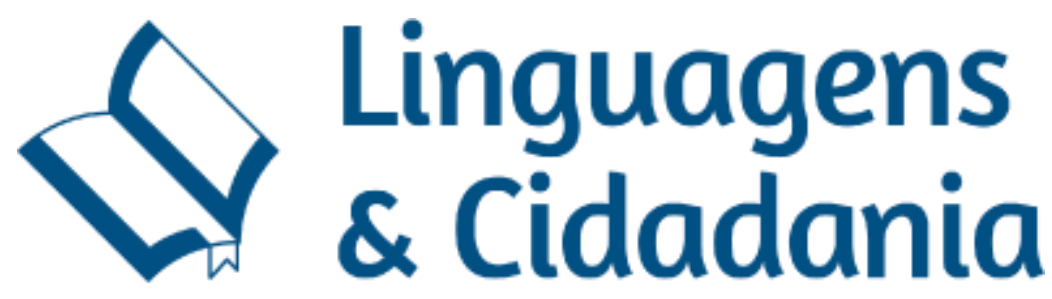

autônoma e independente em todas as esferas da vida, e principalmente, não se sentir invalidada e oprimida pelo simples fato de ser mulher. É importante o estudo acerca da formação de identidade das mulheres inglesas do período histórico em questão, pois os estereótipos formados nesse período são modelos que influenciaram o desenvolvimento de outras mulheres em diversos locais, e são fatos que afetam o modo de pensar e de agir de inúmeras meninas, moças e mulheres ainda hoje.

O debate destes temas nas salas de aulas do século XXI são vitais. Com análises como esta é possível gerar reflexões e questionamentos acerca do modo como o mundo patriarcal se comporta em relação ao sexo oposto e como isso afeta a todos. O século XXI se destaca pela existência dessas inúmeras "janelas" que tornam possível o acontecimento desses diálogos, sem medo de uma possível punição por questionar valores de um regime autoritário que outrora considerava-se inquestionável.

O porquê desta pesquisa envolver um romance autobiográfico ficcional como objeto de estudo acerca de determinados comportamentos, estereótipos e identidades, se deve principalmente à importância da literatura como crítica social e objeto capaz de modificar padrões impostos por uma classe ou gênero dominante como ocorre em Jane Eyre. De acordo com Candido (1995), “a literatura desenvolve em nós a quota de humanidade na medida em que nos torna mais compreensivos e abertos para a natureza, a sociedade, o semelhante".

A importância desta pesquisa, portanto, se deve à maneira como a análise e a interpretação dos dados será realizada para que as conexões estabelecidas possam auxiliar no discernimento de questões importantes como a discriminação de gênero, o controle das massas através das ideologias, assim como a influência de importantes figuras femininas sob gerações futuras, de modo que o resultado desta pesquisa estará a serviço de estudantes, acadêmicos e outros pesquisadores, atuando em favor de interesses sociais pelo tema escolhido (AGUIAR e PEREIRA, 2007). 


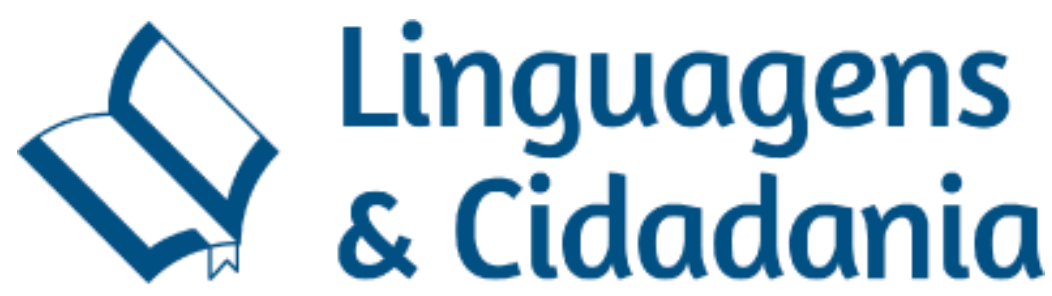

De acordo com Todorov (2007), temos a literatura não apenas como uma porta de ficção para um mundo imaginário mas como meio de crítica de regimes impostos, ideologias que servem como meio de controle social. Nisso, o exercício de ler, refletir e questionar age como um poderoso transformador social, em que cada indivíduo aprende a explorar o seu lado humanizador e respeitoso com o seu semelhante.

A pesquisa, produtora do conhecimento científico, nunca é neutra, mas, como fenômeno político [...] deve se destinar, pois, ao bem-estar das pessoas, na medida em que seus achados possam se transformar em suportes de novos comportamentos. A relação da ciência com a vida prática supõe, por isso, um pesquisador participante, inserido nas contingências de seu meio, disposto a contribuir para a solução das questões que ali se colocam [...] na busca de resolução das mesmas e divulgar suas descobertas de modo a beneficiar a comunidade em que vive (AGUIAR e PEREIRA, 2007, p.14,).

Propõe-se que a presente pesquisa acerca de Jane Eyre forneça uma compreensão de como a escola e a igreja atuam como formadores de valores morais atrelados a ideologias vigentes, assim como uma ferramenta para abordar aspectos da obra como o tema da opressão, discriminação de gênero e empoderamento feminino, não apenas no lar vitoriano, mas na sociedade de classes.

A literatura, no sentido que herdamos da palavra, é uma ideologia. Ela guarda as relações mais estreitas com questões de poder social. Mas, se o leitor ainda não estiver convencido, a narrativa do que aconteceu à literatura em fins do século XIX talvez seja um pouco mais persuasiva (EAGLETON, 2006, p.33).

Desse modo, poderá auxiliar outros estudantes e pesquisadores da área a compreender melhor e debater a influência do estereótipo feminino deste período, que mobilizaram inúmeras mulheres a questionarem assuntos importantes da sociedade e a opressão exercida principalmente pelo sexo masculino, impulsionando-as a buscar equidade e igualdade de direitos diante deles. Poderá, também, estimular a valorização aos estudos literários, sendo a literatura instrumento de denúncia e de construção de opiniões e valores.

\section{CONSIDERAÇÕES FINAIS}




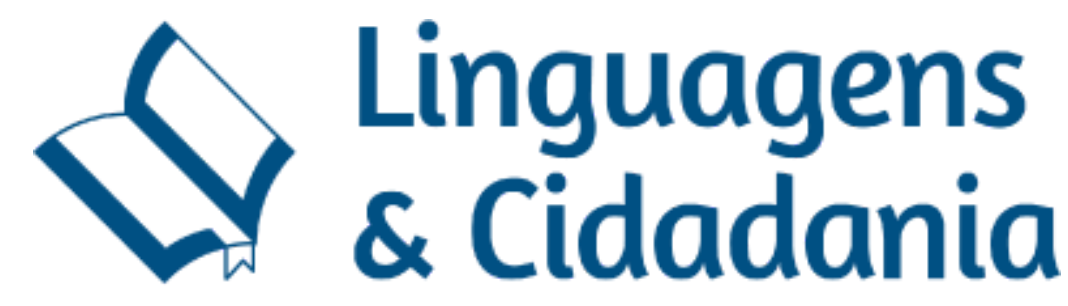

É importante atentar para o papel da literatura na sociedade como produtora de conhecimento, de reflexão crítica, de denúncia de sistemas autoritários, e principalmente, a promoção humanizadora que provoca no sujeito, abrindo portas para outros mundos diferentes daquele em que vivemos, que muitas vezes deixam muito a desejar (CANDIDO, 1995). Assim, compreende-se a importância de pesquisas nesta área, repleta de possibilidades, capaz de promover a reflexão sobre valores antiquados, de longa data ultrapassados, e por inúmeras vezes, desumanos, fornecendo o conhecimento e a possibilidade de uma existência mais humana e mais digna, a qual, segundo a constituição brasileira, todos têm direito (restringindo-se apenas na teoria).

Assim, exploramos na pesquisa a importância da literatura não apenas como uma porta de ficção para um mundo imaginário mas como meio de crítica de regimes impostos, ideologias que servem como meio de controle social. Presente nisso, o exercício de ler, refletir e questionar age como um poderoso transformador social, em que cada indivíduo aprende a explorar o seu lado humanizador e respeitoso com o seu semelhante, independente de sexo, gênero, cor, credo ou etnia.

\section{REFERÊNCIAS}

ACTON, W. The functions and disorders of the reproductive organs. 1. ed. A. \& J. Churchill: London, 1867.

AgUiAR, V. T.; PEREIRA, V. W. (Org.). Pesquisa em Letras. Porto Alegre: Edipucrs, 2007.

BRÖNTE, C. Jane Eyre. Tradução e notas: Doris Goettems. São Paulo: Landmark, 2016.

BEAUVOIR, S. de. O Segundo Sexo: fatos e mitos. Tradução Sérgio Milliet. Rio de Janeiro: Nova Fronteira, $3^{\mathrm{a}}$ ed, [1949] 2016.

CANDIDO, A. Vários Escritos. São Paulo: Duas Cidades, 1995.

EAGLETON, T. Teoria da literatura: uma introdução. São Paulo: Martins Fontes, 2006. 


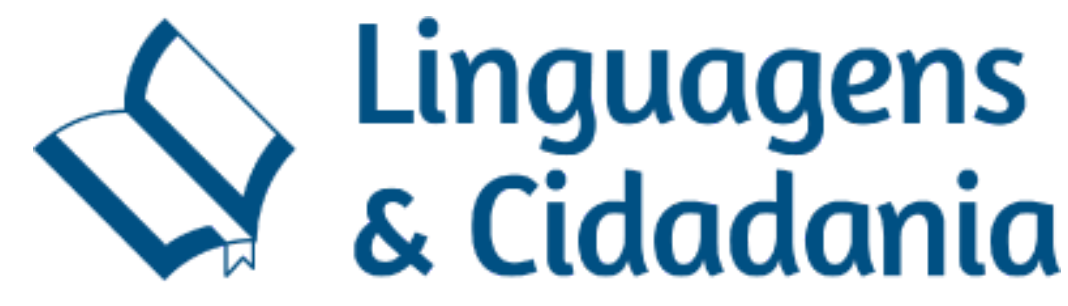

ELLIS, S. The Women of England, their social duties, and domestic habits. New York: D. APPLETON \& CO, 1843.

HALL, S. A Identidade cultural na pós-modernidade. Tradução Tomaz Tadeu da Silva \& Guacira Lopes Louro. Rio de Janeiro: Lamparina, 2015.

MONTEIRO, M. C. Figuras errantes na época vitoriana: a preceptora, a prostituta e a louca. Fragmentos, Florianópolis, v.8, nº1, p.61-71, 1998.

ROSSI, A. D. Seria a pena uma metáfora do falo? A inquietante presença da mulher na literatura. Revista Ícone, Revista de Letras, São Luís de Montes Belos, v.1, p.19-38, 2007.

TODOROV, T. A Literatura em Perigo. Tradução Caio Meira. Rio de Janeiro: DIFEL, 2007. 